\title{
Degradation of specific aromatic compounds migrating from PEXpipes into drinking
} water

Ryssel, Sune Thyge; Arvin, Erik; Lützhøft, Hans-Christian Holten; OIsson, Mikael Emil; Procházková, Zuzana; Albrechtsen, Hans-Jørgen

Published in:

Water Research

Link to article, DOI:

10.1016/j.watres.2015.05.054

Publication date:

2015

Document Version

Peer reviewed version

Link back to DTU Orbit

Citation (APA):

Ryssel, S. T., Arvin, E., Lützhøft, H-C. H., Olsson, M. E., Procházková, Z., \& Albrechtsen, H-J. (2015).

Degradation of specific aromatic compounds migrating from PEXpipes into drinking water. Water Research, 81 , 269-278. https://doi.org/10.1016/j.watres.2015.05.054

\section{General rights}

Copyright and moral rights for the publications made accessible in the public portal are retained by the authors and/or other copyright owners and it is a condition of accessing publications that users recognise and abide by the legal requirements associated with these rights.

- Users may download and print one copy of any publication from the public portal for the purpose of private study or research.

- You may not further distribute the material or use it for any profit-making activity or commercial gain

- You may freely distribute the URL identifying the publication in the public portal 


\section{Degradation of specific aromatic compounds migrating from PEX pipes into drinking water}

Sune Thyge Ryssel ${ }^{1}$, Erik Arvin ${ }^{2 *}$, Hans-Christian Holten Lützhøft ${ }^{3}$, Mikael Emil Olsson $^{4}$, Zuzana Procházková ${ }^{5}$, Hans-Jørgen Albrechtsen ${ }^{6}$

Department of Environmental Engineering, Technical University of Denmark, Miljoevej, Building 113, 2800 Kgs. Lyngby, Denmark ('sury@env.dtu.dk, ²erar@env.dtu.dk, ${ }^{3}$ hhlu@env.dtu.dk, ${ }^{4}$ mieo@env.dtu.dk, ${ }^{5}$ z.prochazkova@aol.com, hana@env.dtu.dk)

*Corresponding author: Tel.: +45 40628153 Fax: +45 45932850 Email address: erar@env.dtu.dk

\section{Highlights}

- 8 aromatic compounds from PEX pipe are partially degraded after 2-4 weeks

- Similar degradation of the compounds in drinking water from different sources

- The specific compounds were not co-metabolized in the presence of acetate

- Only a few percent of the migrating carbon from PE and PEX can be identified 


\title{
Graphical Abstract
}

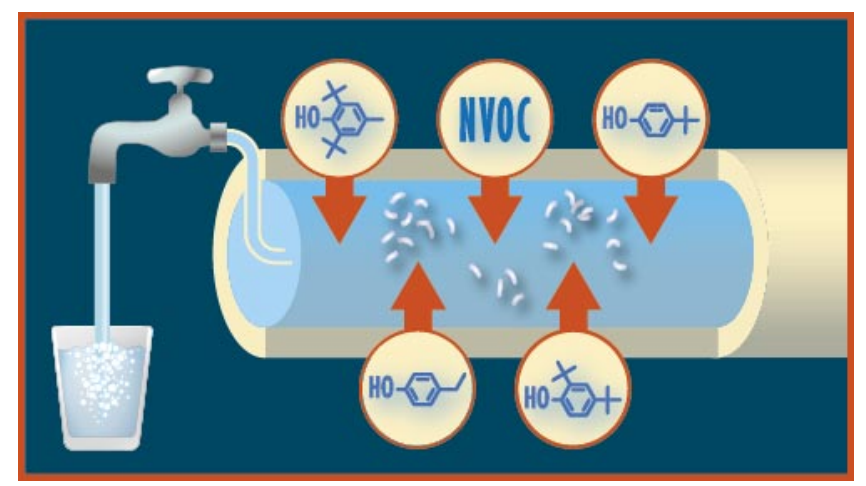

\begin{abstract}
Nine specific compounds identified to migrate from polyethylene (PE) and crosslinked polyethylene (PEX) to drinking water were investigated for their degradation in drinking water. Three sample types were studied: field samples (collected at consumer taps), PEX pipe water extractions, and water samples spiked with target compounds. Four compounds were quantified in field samples at concentrations of 0.15-8.0 $\mu \mathrm{g} / \mathrm{L}$. During PEX pipe water extraction $0.42 \pm 0.20 \mathrm{mg}$ NVOC/L was released and five compounds quantified $(0.5-6.1 \mu \mathrm{g} / \mathrm{L})$. The degradation of these compounds was evaluated in PEX-pipe water extractions and spiked samples. 4-ethylphenol was degraded within 22 days. Eight compounds were, however, only partially degradable under abiotic and biotic conditions within the timeframe of the experiments (2-4 weeks). Neither inhibition nor co-metabolism was observed in the presence of acetate or PEX pipe derived NVOC. Furthermore, the degradation in drinking water from four different locations with three different water works was similar. In conclusion, eight out of the nine compounds studied would - if being released from the pipes reach consumers with only minor concentration decrease during water distribution.
\end{abstract}

\section{Keywords}

Polyethylene pipe, Additives, Migration, Degradation, Drinking water, SPME-GCMS 


\section{Introduction}

Since the 1980's, the polymers PE (polyethylene) and PEX (cross-linked polyethylene) have increasingly replaced materials such as cast iron, concrete and copper in drinking water distribution systems. In Denmark, virtually all new drinking water pipes are made of $\mathrm{PE}$, and they comprised approximately $16 \%$ of the pipeline system in 2002 (Vandpanelet, 2004). The renewal of old pipelines with PE pipes is 0.8-1.5 \% per year. PEX is preferred for household installations because of its flexibility and heat resistance, making it usable for both hot and cold water installations. PE is preferred for larger pipes in distribution systems because of robustness and strength.

Studies of PE and PEX influence on water quality have mainly focused on aftergrowth potentials (e.g. Tsvetanova \& Hoekstra, 2009; Corfitzen et al., 2002 and Van der Kooij et al., 2006) or alteration of odor and taste (e.g. Anselme et al., 1985; Villberg et al., 1998 and Durand \& Dietrich, 2007). Few investigations have focused on the release of specific compounds to drinking water (Brocca et al., 2002; Nielsen et al., 2007; Skjevrak et al., 2003, 2005; Kowalska et al., 2011, and Lund et al., 2011). Increased use of PE and PEX pipes for both new installations and maintenance of existing networks (Vandpanelet, 2004), may increase concentrations of migrating compounds at consumers tap. Elevated biofilm production in PEX pipes compared with copper and stainless steel (Van der Kooij et al, 2005), demonstrates that PEX releases bio-assimilable carbon, i.e. carbon that can be used by microorganisms as source of energy and carbon. However, little is known about the degradability of specific compounds migrating from PEX, how they contribute to the fraction of assimilable carbon or whether the composition of assimilable carbon can affect the degradation of specific compounds. Concentrations of specific compounds in drinking water from household installations are low, i.e. below $2.9 \mu \mathrm{g} / \mathrm{L}$ in field investigations 
and below $5.9 \mu \mathrm{g} / \mathrm{L}$ in laboratory investigations with six new PEX pipes, reported by Nielsen et al. (2007). This investigation included eight of the nine investigated compounds in this study, Table 1(XIV was not included). Lund et al. (2011) measured analyte III and IV in 11 new PEX pipes and found concentrations up to $3.5 \mu \mathrm{g} / \mathrm{L}$ Skjevrak, et al. (2003) measured analytes III, IV and BHT in seven new HDPE pipes with a total concentration of the three analytes up to $4.3 \mu \mathrm{g} / \mathrm{L}$ (Skjevrak, et al., 2005 included analyte III and IV, but only relative concentrations was measured). Kowalska et al. (2011) analyzed one new HDPE pipe for BHT without detection (no detection limit defined). Among these studies, the most frequently quantified analytes were III and IV. In order to determine the concentration profile and homogeneity of antioxidants and degradation products inside a PEX pipe (PEX-a), Denberg et al. (2009) observed concentrations of analyte III in the range $8-27 \mathrm{mg} / \mathrm{kg}$ and analyte IV in the range $1-16 \mathrm{mg} / \mathrm{kg}$.

These low concentrations is challenging for quantification methods. Lützhøft et al. (2013) developed a HS-SPME-GC-MS method (headspace solid phase micro extraction coupled to gas chromatography with mass spectrometry detection) which allows analysis in the low $\mu \mathrm{g} / \mathrm{L}$ range with analyte dependent limits of detection (LOD) in the range $0.15-0.50 \mu \mathrm{g} / \mathrm{L}$.

During hazard identification of chemicals in the environment, the three most critical parameters are: persistency, bioaccumulation and toxicity. However, little is known regarding these parameters in relation to migrating compounds from PE/PEX in drinking water. Persistence in terms of biodegradability was calculated for the nine specific compounds (Table 1) using the software program EPI Suite (US EPA, 2012), based on the work of Howard et al. (1992).

Table 1 - Analytes quantified in the experiments with name, limit of detection (LOD), limit of quantification (LOQ) and structure presented. Chemical properties, purities and suppliers can be found in the supplementary data.

\begin{tabular}{|c|c|c|c|}
\hline Analyte ID & $\begin{array}{l}\text { Chemical name } \\
\text { (CAS no.) }\end{array}$ & $\begin{array}{c}\text { LOD } \\
\text { LOQ } \\
\text { [ug/L] }\end{array}$ & Structure \\
\hline
\end{tabular}




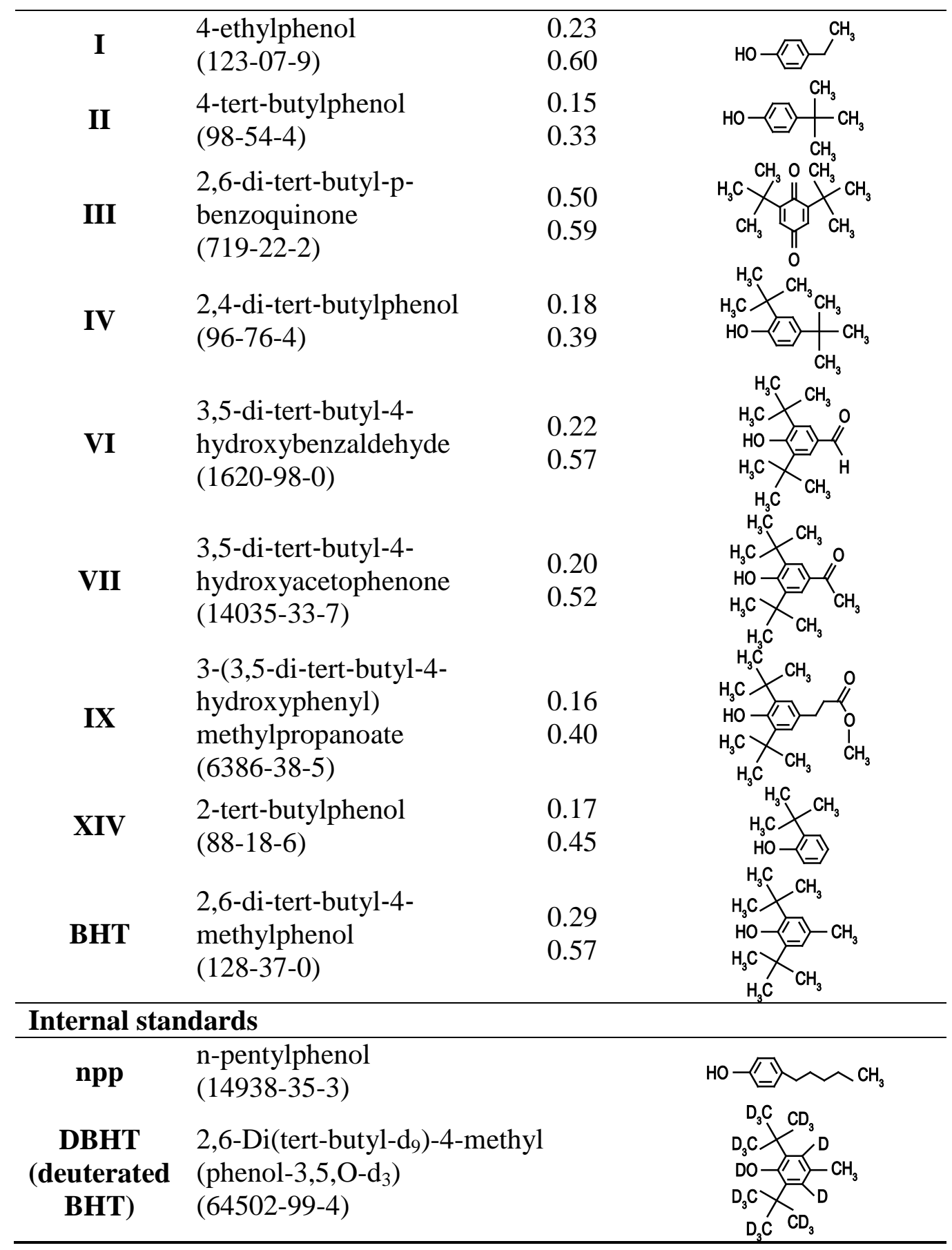

The estimation model is based on data relating to environmental fate, e.g. in surface water. However, the degradation potential in drinking water may be less than estimated, since the biomass concentration is lower in drinking water compared with surface water. Four of the nine compounds were classified as "not fast biodegradable" by the linear and non-linear biodegradation model in EPI Suite (US EPA, 2012). Within the European legislation REACH substances are assessed for their (potential) bioaccumulation. If no experimental bioconcentration factors (BCFs) exist, estimation is made from the octanolwater partitioning coefficient $\left(\mathrm{K}_{\mathrm{ow}}\right)$. If a compound has a log 
$\mathrm{K}_{\mathrm{Ow}}$-value above 4,5, it is considered potentially bioaccumulating (European Chemicals Agency, 2012). Three of the nine investigated compounds have log $\mathrm{K}_{\mathrm{ow}}$ $>4.5$ (see supplementary material), and are thus considered potentially bioaccumulating. A recent QSAR model (Quantitative structure-activity relationship) by the Danish EPA on the toxicity of eight of the nine compounds indicated that two compounds (analyte VI and IX) have potential to be allergenic, carcinogenic and genotoxic. Consequently, the Danish EPA suggested a guideline value of $1 \mu \mathrm{g} / \mathrm{L}$ in drinking water (Miljoestyrelsen, 2007). These estimations coupled with the lack of experimental data highlight the value in measuring the degradation potential for the nine compounds in drinking water with concentrations in relevant ranges (level 2 testing (European Commission, 2003)).

Thus the aim of this investigation was to assess the degradation potential in drinking water for nine specific compounds (referred to as analytes and listed in Table 1) identified mainly by Brocca et al. (2002). The analytes are aromatic compounds which are antioxidants, degradation products of antioxidants and/or additives in PE/PEX. This study explored biotic and abiotic degradation, if degradation was promoted by the presence of easily biodegradable dissolved organic carbon (acetate) (co-metabolism) or if dissolved organic carbon from a PEX extract affected the removal of the analytes. Furthermore, the degradation was investigated for the analytes in drinking water from different sources and associated with different pipe material. In this article, “degradation” is synonymous with "removal” and may be due to biotic or abiotic transformation and mineralization.

\section{Materials and Methods}

\subsection{Experimental approach and sampling locations}

Degradation of analytes was studied in water samples obtained from: a) four household installations in Denmark with public water supply and distribution systems 
containing PE pipes; b) stagnant extraction in a PEX pipe; and c) water samples representing four different test environments spiked with pure analytes (Table 1). The four locations sampled were: location 1) a laboratory building at the Technical University of Denmark in Kgs. Lyngby (an approximately 40 year old building with galvanized steel pipes, NVOC concentration in water $2.4 \mathrm{mg} \mathrm{C} / \mathrm{L}$ ), location 2) a kindergarten in Ulleroed/Hilleroed (a building less than 6 years old with PEX pipes, NVOC concentration in water $3.7 \mathrm{mg} \mathrm{C/L}$ ), location 3) a public school in Ulleroed/Hilleroed (a building less than 4 years old with PEX pipes, NVOC concentration in water $3.7 \mathrm{mg} \mathrm{C} / \mathrm{L}$ ), and location 4) a private house at a newly developed residential area in Farum (less than 6 years old with PEX pipes, NVOC concentration in water $3.3 \mathrm{mg} \mathrm{C} / \mathrm{L}$ ). The sampling locations represented three different water supplies, since location 2 and 3 were supplied by the same water works in Ulleroed/Hilleroed.

The proportion of PE pipes in the distribution systems upstream of the four locations is very different. At location 1 , approximately $2 \%$ of the distribution system is made of PE; the rest is made of cast iron, galvanized steel and Eternite. At locations 2 and 3, approximately $50 \%$ consisted of PE and 50\% of PVC. At location 4, $100 \%$ consisted of PE because it is a newly developed area.

The selected locations allowed for investigation of differences in analyte degradability between waterworks, different placements within the same distribution system and different proportions of PE in the distribution system. All drinking water used was non-chlorinated groundwater and collected at $10 \pm 2{ }^{\circ} \mathrm{C}$. The hardness of the groundwater ranged between 280-320 $\mathrm{mg} \mathrm{CaCO}_{3} / \mathrm{L}$ among the locations.

\subsection{Experimental set up}

Four experiments $(\mathrm{A}-\mathrm{D})$ were conducted as follows: 
A) Field study of three household installations with PEX pipes. Drinking water was collected from locations 2, 3 and 4 after a stagnation period of a weekend (approximately 63 hours) at different locations in each building and the analyte concentrations determined. At each location a sample was taken immediately after opening the tap, in order to represent the stagnant water in the pipes closest to the tap. Additional samples were then taken after 0.1-20 L of discharge, so water from the remaining pipes in the building was attained. Samples were collected in $100 \mathrm{~mL}$ Pyrex glass bottles, stored at $4^{\circ} \mathrm{C}$ and analyzed the same day or the next day.

B) Investigation of analyte and NVOC degradability in a PEX-c pipe extraction using sterilized MilliQ water. After extraction, the water samples were inoculated with $1 \% \mathrm{w} / \mathrm{w}$ of drinking water from location 1 and the concentration of the analytes and microbial activity observed over a period of 27 days.

C) Investigation of degradation in four different media using water samples spiked with pure analytes. The media were: C-1) Mineral medium (sterile filtered MilliQ water with nutrient salts (Van der Kooij et al., 2006), n=3); C-2) acetate medium (sterile filtered MilliQ water with nutrient salts and $500 \mu \mathrm{g}$ C-acetate/L, n=3); C-3) PEX extraction (MilliQ water extraction with nutrient salts, n=2) and C-4) drinking water (location $1, n=3$ ). Abiotic controls $(n=3)$ were set up with autoclaved PEX extract and drinking water. The water samples were spiked to a concentration of $5 \mu \mathrm{g} / \mathrm{L}$ for each analyte with the direct spiking technique (described in section 2.4), since the technique delivers all analytes. All incubations were inoculated with drinking water from location $1(1 \% \mathrm{w} / \mathrm{w})$. Each incubation was analyzed 7 times during 22 days of incubation. Autoclaving samples reduced the concentration of some of the analytes, resulting in a lower initial concentration in the degradation experiments, but this was considered not to affect the degradation potential of the analytes. 


\section{D) Investigation of analyte degradation in drinking water from different}

locations. An analyte spiked experiment was conducted with drinking water from the four locations: 1, 2, 3 and $4(\mathrm{n}=3)$. A spiking technique with coating (described in section 2.4) was used for this experiment, as this technique does not introduce residual carbon to the samples. Abiotic controls $(n=3)$ were set up in order to distinguish abiotic removal from biological degradation. Abiotic conditions were verified because ATP was below LOQ (1.29 pg ATP/mL). The samples were analyzed at day 1 and 14.All incubations were conducted in the dark at $20^{\circ} \mathrm{C}$.

A preliminary investigation showed that there was no significant adsorption of analytes to the glass surfaces in the glass bottles.

\subsection{PEX pipe and extraction procedure}

The investigated PEX-c pipe (Wavin, Tigris PEX-One, 15x2.5 mm, 25.3.2008, Danish VA approval) is certified for cold water and hot water installations.

Prior to investigation, the pipe had been exposed to the equivalence of $1 \frac{1 / 2}{2}$ month normal use and subsequent flushed with sterile filtered MilliQ water. The sample pipe section was 40 meters long with a diameter of 10/15 mm (inner/outer). During extraction the pipe was sealed with stainless steel fittings, which were rinsed with MilliQ water and heated to $550^{\circ} \mathrm{C}$ for four hours before use. The pipe was extracted for 72 hours at $37^{\circ} \mathrm{C}$ with stagnant sterile filtered MilliQ water. The time periode $72 \mathrm{~h}$ is in accordance with European standard EN 12873-1.

\subsection{Spiking with analytes}

Two spiking techniques were used: 1) Direct spiking with a diluted methanol stock and, 2) Coating using n-pentane as solvent.

For the direct spiking technique, a methanol stock solution containing all nine analytical grade analytes was prepared with a concentration of $400 \mathrm{mg} / \mathrm{L}$ for each 
analyte. Subsequently the final diluted stock was prepared with MilliQ water to a concentration of $10 \mathrm{mg} / \mathrm{L}$ for each analyte before the $1 \mathrm{~L}$ test bottles were spiked with $0.5 \mathrm{~mL}$ of the diluted stock, giving a final concentration of $5 \mu \mathrm{g} / \mathrm{L}$ for each analyte. The direct spike technique has the disadvantage of adding residual carbon of $3710 \mu \mathrm{g}$ methanol-C/L to the samples from methanol; however, this technique includes all analytes and is highly simplistic.

The coating technique was conducted with analytical grade pure n-pentane stock and $1 \mathrm{mg} / \mathrm{L}$ of each analyte. Incubation bottles were spiked while placed horizontally on a roller mixer. Subsequently the n-pentane stock $(5 \mathrm{~mL})$ was transferred to the rotating bottle and the volume of the bottle was replaced 3 times with pure nitrogen gas (airflow of $0.5 \mathrm{~L} / \mathrm{s}$ ) for 10 seconds and with a pause of 10 seconds. Bottles were then closed and kept in the dark at room temperature for less than 24 hours before use.

The coating technique leaves no residual carbon from the solvent (n-pentane) in the sample; however, three analytes (I, XIV and BHT) were significantly lost due to evaporation. Consequently, it was not possible to measure the degradation of analyte I, XIV and BHT with the coating technique.

\subsection{Test bottles, sample vials and equipment}

Degradation experiments (B, C and D) were conducted in 1L Pyrex glass bottles and sealed with Teflon lined polypropylene screw caps. Bottles and caps were washed with acid, rinsed with MilliQ water and heated (bottles: $550^{\circ} \mathrm{C}$ for four hours and caps: $180^{\circ} \mathrm{C}$ for six hours). Vials for measurements of non-volatile organic carbon (NVOC) and GC-MS analysis were acid washed and rinsed with MilliQ water. Vials for NVOC measurements were furthermore heated to $550^{\circ}$ for four hours in order to remove all carbon. 


\subsection{Sample preparation for GC-MS analysis}

Water samples of $10.0 \mathrm{~mL}$ were collected in $20 \mathrm{~mL}$ threaded glass vials and sealed with an open steel cap and Teflon/silicone septa. Additionally $100 \mu \mathrm{L}$ of $500 \mu \mathrm{g} / \mathrm{L} \mathrm{n}$ pentylphenol (npp) and $100 \mu \mathrm{L}$ of $500 \mu \mathrm{g} / \mathrm{L}$ deuterated BHT (DBHT) was added as internal standards and $100 \mu \mathrm{L}$ of phosphate buffer $\left(45 \mathrm{mM} \mathrm{NaH} \mathrm{PO}_{4} \cdot \mathrm{H}_{2} \mathrm{O}\right.$ and $22 \mathrm{mM}$ $\mathrm{H}_{3} \mathrm{PO}_{4}$ ) was also introduced to maintain a $\mathrm{pH}$ in the range of 2.6-3.1 in all samples regardless of matrix. Internal standards and buffer were added immediately after the samples were drawn. Samples were stored at $4^{\circ} \mathrm{C}$ in the dark for no more than eight days before analysis.

\subsection{Statistical method}

To distinguish between biotic- and abiotic degradation of analytes in the direct spiking experiment (C), initial concentrations were statistically compared to the final concentration at the end of the experiment. The concentration on day 2 tended to be higher than at day 0 , and since this could not be explained analytically, the measurements at day 0 and 2 were pooled to represent the initial concentration. The final concentration was represented by pooled measurements at day 15, 18 and 22. For the experiments using the coating technique (D) measurements at day 1 and 14 were compared.

The t-test was used as a guide to determine whether a decrease over time was significant or not. Initial and final concentrations were compared by an unpaired (unequal variance) one-tailed t-test (MS Excel 2010) with a significance level of 5\%, using the null hypothesis $\mathrm{H}_{0}: \mu_{\text {final }}=\mu_{\text {start }}$ and the alternative hypothesis $\mathrm{H}_{1}: \mu_{\text {final }}<$ $\mu_{\text {start }}$ Randomization of the samples was not possible due to practical reasons. To investigate the effect of the test conditions, i.e. abiotic and biotic degradation, and the difference between the four studied locations, a two-way ANOVA test using the 
statistical program R (R Core Team, 2014) was employed. The significance level was set to $5 \%$.

Measurements below LOD were set to $50 \%$ of the LOD for all experiments whilst samples with signals less then background peaks were set to zero.

\subsection{Analytical methods}

\section{GC-MS quantification method}

The analytes were quantified by an HS-SPME-GC-MS method (Lützhøft et al., 2013) modified by adding deuterated BHT of analytical grade (listed in Table 1) as an internal standard for quantification of BHT.

The calibration range was $0.1-6.0 \mu \mathrm{g} / \mathrm{L}$ for all analytes. The limit of detection (LOD) and limit of quantification (LOQ) for the GC-MS method were calculated from background measurements ( $\mathrm{n}=7$ ) of MilliQ water and standard deviations $(\mathrm{n}=6)$ of the lowest standard concentration. Three (LOD) and ten (LOQ) times the standard deviation were added to background measurements for calculation of analytical limits. The LOD's for the analytes can be seen in Table 1.

\section{Non-volatile organic carbon analysis}

For NVOC analysis, $40 \mathrm{~mL}$ of sample was collected in glass vials and preserved with $50 \mu \mathrm{L} 17 \%$ w/w $\mathrm{H}_{3} \mathrm{PO}_{4}$. The opening of the vials was wrapped with aluminum foil before sealing with a plastic cap lined with Teflon on the inside. Samples were stored at $4^{\circ} \mathrm{C}$ before analysis was undertaken within nine days. NVOC was measured according to standard method 5310C (APHA, 1992). A seven point calibration curve was prepared in triplicate with concentrations between 0 and $5000 \mu \mathrm{g}$ C/L. The LOD and LOQ were $70 \mu \mathrm{g}$ C/L and $240 \mu \mathrm{g}$ C/L respectively. 


\section{Microbial analysis}

Total adenosine triphosphate (ATP) concentrations were measured with a bioluminometric analysis method on a Celsius Advance Coupe instrument (Vang et al., 2014). The quantification method is based on enzymes reacting with ATP, to emit light proportional with the ATP concentration.

Samples $(1.5 \mathrm{~mL})$ were stored in Eppendorf tubes at $-80^{\circ} \mathrm{C}$ until analysis, which occurred in less than six weeks. Based on a seven point calibration curve in the range of 0.2 to $750 \mathrm{pg} \mathrm{ATP} / \mathrm{mL}$ and an ordinary least squares linear regression, the relative light units were converted into an ATP concentration. Four replicates of the seven point calibration series were spread out over the analytical run as a control for variation caused by temperature changes in the laboratory during the analytical run.

The LOD (0.57-0.83 pg ATP/mL) and LOQ (2.02-2.97 pg ATP/mL) were calculated from background measurements and margins of three and ten times the analytical variation in the low concentration range $(0-10 \mathrm{pg}$ ATP/mL).

For heterotrophic plate count (HPC) the spread plate technique used $50 \mu \mathrm{L}$ of sample on a plate of $\mathrm{R}_{2} \mathrm{~A}$ agar (Reasoner \& Geldreich, 1985) from Oxiod Denmark. Four dilutions $\left(10^{0}, 10^{-1}, 10^{-2}\right.$, and $\left.10^{-3}\right)$ were prepared for each sample and plated in triplicates. The agar dishes were incubated for seven days in the dark at $20^{\circ} \mathrm{C}$ before colonies were counted. The results were calculated as a weighted average between the total volume spread and number of colonies formed.

\section{Results and discussion}

\subsection{Field investigation}

In the field investigation several analytes (III, IV, VI and BHT) were detected and quantified in drinking water at the consumer's tap (location 2-4, Table 2). Analyte III was the most frequently detected with concentrations up to $8.0 \mu \mathrm{g} / \mathrm{L}$. Analyte III was also detected at all sampling points at the three locations. 
Table 2 - Concentration of analytes in drinking water samples collected at three households with PEX installations (exp. A). Concentrations in bold are measurements below limit of detection.

\begin{tabular}{|c|c|c|c|c|}
\hline Location & Sampling point & $\mathbf{n}$ & Analytes & Concentration $[\mu \mathrm{g} / \mathrm{L}]$ \\
\hline \multirow{5}{*}{2} & & & III & 0.25-0.74 \\
\hline & Kitchen & 2 & VI & 0.11-0.22 \\
\hline & & & BHT & $0-0.15$ \\
\hline & Bathroom 1 & 3 & III & $0.25-0.83$ \\
\hline & Bathroom 2 & 5 & III & 0.25 \\
\hline \multirow{5}{*}{3} & Bathroom 1 & 2 & III & $0.85-2.2$ \\
\hline & & & III & 0.25-1.3 \\
\hline & Bathroom 2 & 2 & VI & $0-\mathbf{0 . 1 1}$ \\
\hline & & & BHT & 0-0.15 \\
\hline & Cleaning room & 4 & III & $0.70-1.8$ \\
\hline \multirow{3}{*}{4} & & & III & $5.6-8.0^{*}$ \\
\hline & Shower tap & 3 & IV & $0.90-0.31$ \\
\hline & & & VI & 0-0.72 \\
\hline
\end{tabular}

* Extrapolated concentration from calibration between 0.1 and $6.0 \mu \mathrm{g} / \mathrm{L}$

Nielsen et al, 2007 also observed analyte III and IV in field samples from household installations, and identified analyte III as the most frequently detected (quantified in four out of six locations) and with the highest concentration $(2.9 \mu \mathrm{g} / \mathrm{L})$. The presence of these compounds in drinking water at the point of consumption makes it pertinent to conduct further investigations regarding these specific compounds.

The analytes included in this study have been studied by the Danish EPA. A QSAR model previously suggested a guideline value of $1 \mu \mathrm{g} / \mathrm{L}$ for two of the analytes (VI and IX) (Miljoestyrelsen, 2007) - only slightly higher than the concentrations of up to $0.72 \mu \mathrm{g} / \mathrm{L}$ which were detected in the field investigation (A).

\subsection{Migration from a PEX pipe}

Analytes III, IV, VI, VII, and IX were detected in the concentrations range of 0.5-6.1 $\mu \mathrm{g} / \mathrm{L}$ (Table 3) in drinking water which had been in contact with the PEX pipe for 72 hours. Three out of four analytes detected in the field investigation were also detected in the PEX pipe extraction. Analyte III had the highest concentration in both the extraction and in the field. 
Table 3 - Calculation of the analytes contribution to NVOC in PEX extraction after stagnation for 72 hours at $37^{\circ} \mathrm{C}$ (exp. B)

\begin{tabular}{c|cccccc}
\hline Analyte & $\begin{array}{c}\text { Molecular } \\
\text { formula }\end{array}$ & $\begin{array}{c}\mathrm{M}_{\text {analyte }} \\
{[\mathrm{g} / \mathrm{mole}]}\end{array}$ & $\begin{array}{c}\mathrm{M}_{\text {carbon }} \\
{[\mathrm{g} / \mathrm{mole}]}\end{array}$ & $\begin{array}{c}\mathrm{M}_{\mathrm{c}} / \mathrm{M}_{\text {analyte }} \\
\mu \mathrm{g} \text { analyte/L }\end{array}$ & $\mu \mathrm{g}$ carbon/L \\
\hline I & $\mathrm{C}_{8} \mathrm{H}_{10} \mathrm{O}$ & 122.16 & 96.09 & 0.79 & 0.0 & 0 \\
II & $\mathrm{C}_{10} \mathrm{H}_{14} \mathrm{O}$ & 150.22 & 120.11 & 0.80 & 0.0 & 0 \\
III & $\mathrm{C}_{14} \mathrm{H}_{20} \mathrm{O}_{2}$ & 220.31 & 168.15 & 0.76 & $6.1 \pm 2.3$ & 4.7 \\
IV & $\mathrm{C}_{14} \mathrm{H}_{22} \mathrm{O}$ & 206.33 & 168.15 & 0.81 & $0.5 \pm 0.2$ & 0.4 \\
VI & $\mathrm{C}_{15} \mathrm{H}_{22} \mathrm{O}_{2}$ & 234.34 & 180.16 & 0.77 & $1.7 \pm 0.3$ & 1.3 \\
VII & $\mathrm{C}_{16} \mathrm{H}_{24} \mathrm{O}_{2}$ & 248.37 & 192.17 & 0.77 & $0.5 \pm 0.1$ & 0.4 \\
IX & $\mathrm{C}_{18} \mathrm{H}_{28} \mathrm{O}_{3}$ & 292.42 & 216.19 & 0.74 & $0.6 \pm 0.1$ & 0.4 \\
XIV & $\mathrm{C}_{10} \mathrm{H}_{14} \mathrm{O}$ & 150.22 & 120.11 & 0.80 & 0.0 & 0 \\
BHT & $\mathrm{C}_{15} \mathrm{H}_{24} \mathrm{O}$ & 220.35 & 180.16 & 0.82 & 0.0 & 0 \\
\hline Total & & & & 9.4 & 7.2 \\
& \\
Extracted NVOC: & \\
Percentage of NVOC as analytes:
\end{tabular}

* Means are shown for four replicates \pm one standard deviation (one sample before inoculation and three replicates after inoculation). Background measurements were conducted in duplicates and none of the analytes were detected in the MilliQ water before extraction, with the exception of analyte VII which had a background concentration $(0.2 \mu \mathrm{g} / \mathrm{L})$.

Total NVOC concentration also increased with $0.42 \pm 0.20 \mathrm{mg}$ NVOC/L $(n=4)$ to $0.556 \mathrm{mg}$ NVOC/L during contact with PEX. In another study extractions at $23^{\circ} \mathrm{C}$ of new PEX-a and PEX-c pipes released up to $5.1 \mathrm{mg}$ NVOC/L (Nielsen et al., 2007).

The fraction of NVOC represented by the analytes in the extraction was calculated to $1.7 \%$ (Table 3). The remaining approximately $98 \%$ of NVOC was unidentified.

A previous study (Nielsen et al., 2007) showed a contribution from the analytes (without analyte XIV) in a range of $0.09-6.3 \%$ of the NVOC. This shows that currently only a small fraction of the migrating carbon can be quantified as specific compounds. Bucheli-Witschel et al., (2012), suggest that migration of short chain polymeric units could contribute to NVOC concentrations. However, since only a small fraction of the migrating carbon can be quantified by specific chemical analysis, it remains unknown what is actually migrating into the drinking water from the polymer pipes. 


\subsection{Degradation of NVOC from a PEX pipe}

The majority (90\%) of the NVOC from the PEX pipe was degraded within 9 days (Figure 1).
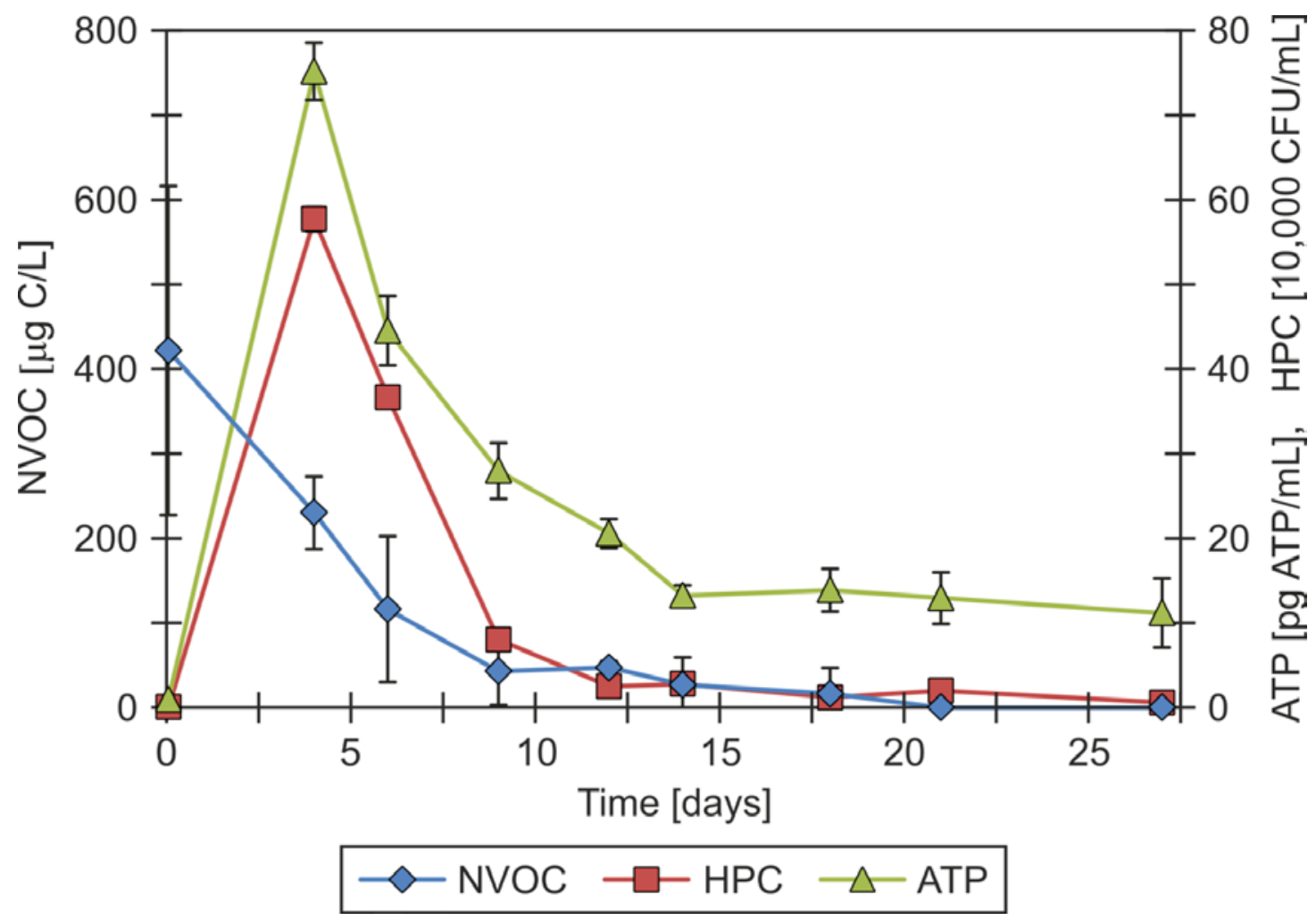

Figure 1. NVOC, HPC, and ATP concentrations during incubation of water extraction from a PEX pipe (exp. B). The NVOC concentrations have the background concentration of $134 \pm 37 \mu \mathrm{g}$ C/L subtracted. All data points are triplicates (NVOC on day 0 in 4 replicates: One before inoculation and three after inoculation) and the error bars indicate \pm one standard deviation. The batches were inoculated with drinking water (1\%) from location 1.

The NVOC was obviously a substrate for the microorganisms since the heterotrophic plate count (HPC) and ATP increased concomitantly with the NVOC removal and declined when most of the NVOC had been consumed from the extraction water (B). This clearly indicated biodegradation of NVOC by the naturally occurring microorganisms in drinking water, which was supported by the stable NVOC concentration for the entire incubation period in the abiotic controls. Similar results were obtained in the direct spiking experiments (C) (data not shown). The findings were in accordance with previous observation of assimilation of leached carbon from PE (Corfitzen, 2004). 


\subsection{Degradation of analytes}

The concentration of all analytes generally decreased over time in the degradation experiments when initial and final concentrations for the analytes in the direct spiking experiment (C) were compared (Table 4, all data in supplementary material). Four analytes decreased with statistical significance in abiotic incubations while eight analytes were degraded with statistical significance in the biotic incubation samples where abiotic and microbiological degradation took place. Only analyte I and VI were removed to below LOD in the direct spiking experiment (C).

Table 4 - Comparison of initial and final concentrations for incubation samples directly spiked with analytes (exp. C) with a statistical t-test for both abiotic and biotic incubation together with EPI Suite estimations of biodegradability. Incubation time was 4 weeks.

\begin{tabular}{cccccccccc}
\hline Analytes & \multicolumn{3}{c}{ Abiotic incubation } & \multicolumn{3}{c}{ Biotic incubation } & & EPI Suite \\
& $\begin{array}{c}\text { Abiotic } \\
\text { removal }\end{array}$ & $\mathrm{n}_{\text {initial }}$ & $\mathrm{n}_{\text {final }}$ & $\mathrm{p}$-value & $\begin{array}{c}\text { Biodegradation } \\
\text { + abiotic } \\
\text { removal }\end{array}$ & $\mathrm{n}_{\text {initial }}$ & $\mathrm{n}_{\text {final }}$ & p-value & $\begin{array}{c}\text { Estimated } \\
\text { biodegrada- } \\
\text { bility }\end{array}$ \\
\hline I & $37 \%$ & 6 & 9 & $\mathbf{0 . 0 1 3}$ & $100 \%$ & 22 & 33 & $<\mathbf{0 . 0 0 1}$ & Fast \\
II & $28 \%$ & 6 & 9 & $\mathbf{0 . 0 2 5}$ & $31-36 \%$ & 22 & 33 & $<\mathbf{0 . 0 0 1}$ & Fast \\
III & $*$ & 6 & 9 & 0.160 & $48-81 \%$ & 22 & 33 & $<\mathbf{0 . 0 0 1}$ & Not fast \\
IV & $26-32 \%$ & 3 & 9 & 0.185 & $27-34 \%$ & 11 & 32 & $<\mathbf{0 . 0 0 1}$ & Not fast \\
VI & $48-56 \%$ & 6 & 9 & 0.088 & $87-98 \%$ & 22 & 33 & $<\mathbf{0 . 0 0 1}$ & Fast \\
VII & $42-57 \%$ & 6 & 9 & $\mathbf{0 . 0 0 9}$ & $54-59 \%$ & 22 & 33 & $<\mathbf{0 . 0 0 1}$ & Not fast \\
IX & $46 \%$ & 3 & 9 & 0.281 & $49-77 \%$ & 11 & 31 & $<\mathbf{0 . 0 0 1}$ & Fast \\
XIV & $29-35 \%$ & 6 & 9 & $\mathbf{0 . 0 4 6}$ & $28-42 \%$ & 22 & 33 & $<\mathbf{0 . 0 0 1}$ & Fast \\
BHT & $9-17 \%$ & 6 & 9 & 0.258 & $7-27 \%$ & 22 & 33 & 0.326 & Not fast \\
\hline
\end{tabular}

Note: Bold $\mathrm{p}$-values indicates significant values $(\mathrm{p}<0.05)$ with a significance level of $5 \%$. Removal was calculated as the ratio between final and initial concentration.

*Inconclusive results because of low initial concentrations.

Analyte I was removed in all biologically active bottles, decreasing from 4-5 $\mu \mathrm{g} / \mathrm{L}$ to $0 \mu \mathrm{g} / \mathrm{L}$ within four days. Analyte VI fell below the LOD in one biotic sample bottle and reached concentrations close to LOD in the remaining two biotic bottles. Analyte II, III, IV, VII, IX and XIV were all partially removed during biotic incubation and analyte BHT indicated minor degradation (7-27\% removal), however BHT was not statistically significant degraded in the direct spiking experiment (C). Figure 2 shows the degradation of the three analytes (III, IV, and VI) which were the most frequently detected in the literature and in our samples (both in field (A) and extraction samples (B)) . The degree of biotic degradation was similar in both the extraction and direct 
spiking experiments ( $B$ and $C$ respectively). In the extraction experiment (B) five analytes (III, IV, VI, VII, and XI) decreased partially, although statistically significant, in concentration over time, with the exception of analyte III.

Removal of analytes in experiments C (direct spiking) and D (degradation in drinking water) were compared and the degradation tendencies observed were highly similar (Table 4 and Figure 3).

The different analyte introduction techniques employed (direct spiking (C) and the coating technique in experiment (D)) were compared in order to determine if residual methanol associated with direct spiking affected degradation. Furthermore, experiment (D) was replicated for location 1 and 2 with direct spiking (not shown), and degradation tendencies were highly similar between the two analyte introduction techniques. Consequently, the residual carbon introduced to samples during the direct spiking technique did not affect the degradation of analytes. 

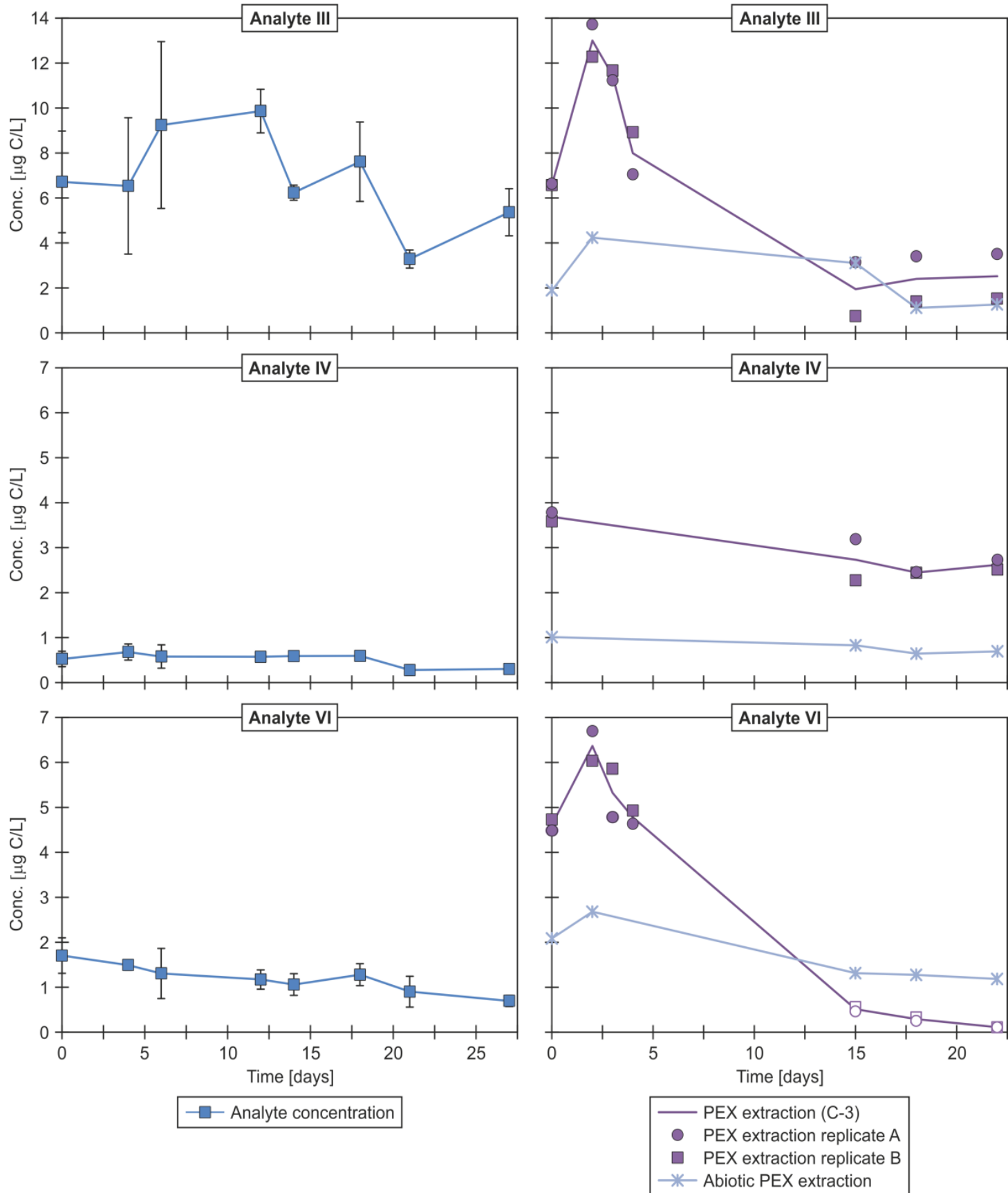

Figure 2. Degradation of selected analytes in extractions from a PEX pipe (exp. B) and for extraction spiked with $5 \mu \mathrm{g} / \mathrm{L}$ of each analyte (exp. C-3). No data available for analyte IV in the spiked extraction at day 2, 3 and 4. Error bars indicate \pm one standard deviation of three replicates. Hollow symbols indicate measurements below LOQ. 

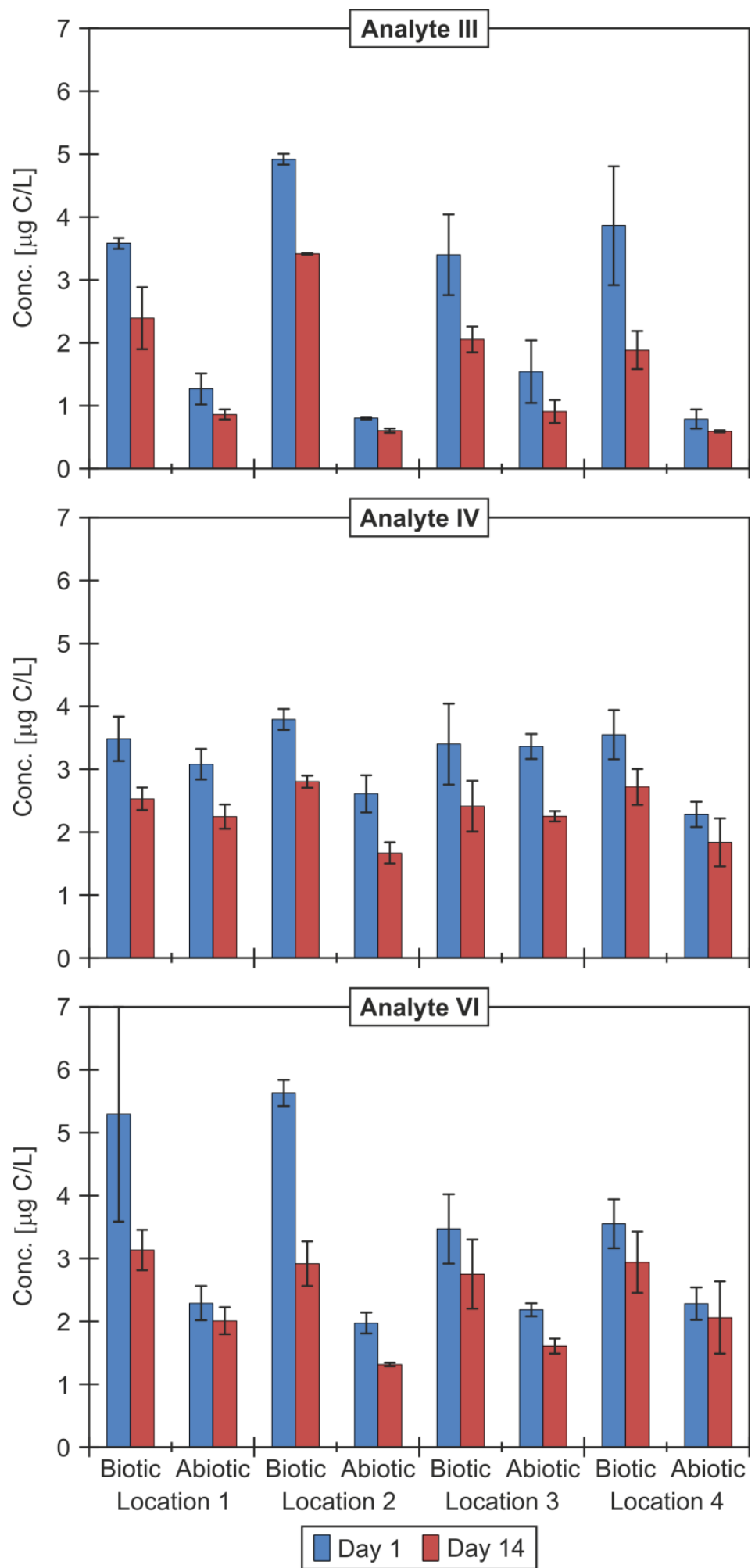

Figure 3. Concentration in biotic and abiotic drinking water samples from four different locations spiked with analytes (exp. D) for analyte III, IV and VI. Each bar represents mean of triplicates and error bars indicate \pm one standard deviation. 


\subsection{Inhibition and co-metabolic effects on biodegradation}

To assess the impacts of varying media on degradation potential, relative concentrations in the four media types studied (C-1, C-2, C-3 and C-4) were compared. None of the analytes differed in degradation between the four test media. The degradation of the three most frequently detected analytes (III, IV, and VI) are shown in Figure 4. There was no significant difference between degradation for any of the nine analytes in mineral medium (C-1) nor when adding either acetate $(\mathrm{C}-2)$ or in the presence of NVOC from the PEX pipe (C-3). The addition of acetate to the mineral medium increased the microbial activity, but the overall degradation of the analytes was not affected compared to samples without acetate addition. Therefore, no stimulating co-metabolic effects were detected in the presence of acetate as an easily assimilable carbon source.

Degradation in samples with extraction from the PEX pipe (C-3) was similar to the degradation in mineral medium (C-1) and thus the composition of leached NVOC had no impact on degradation of analytes. Consequently, neither acetate nor NVOC from PEX affected the degradation of analytes in drinking water. Furthermore, degradation was similar in both mineral medium (C-1) (initial NVOC concentration: 1.8-2.2 mg $\mathrm{C} / \mathrm{L}$ ) and drinking water (C-4) (initial NVOC concentration: 4.1-4.2 mg C/L), thus no co-metabolic effect or inhibition was observed with easy assimilable carbon or NVOC from PEX. 

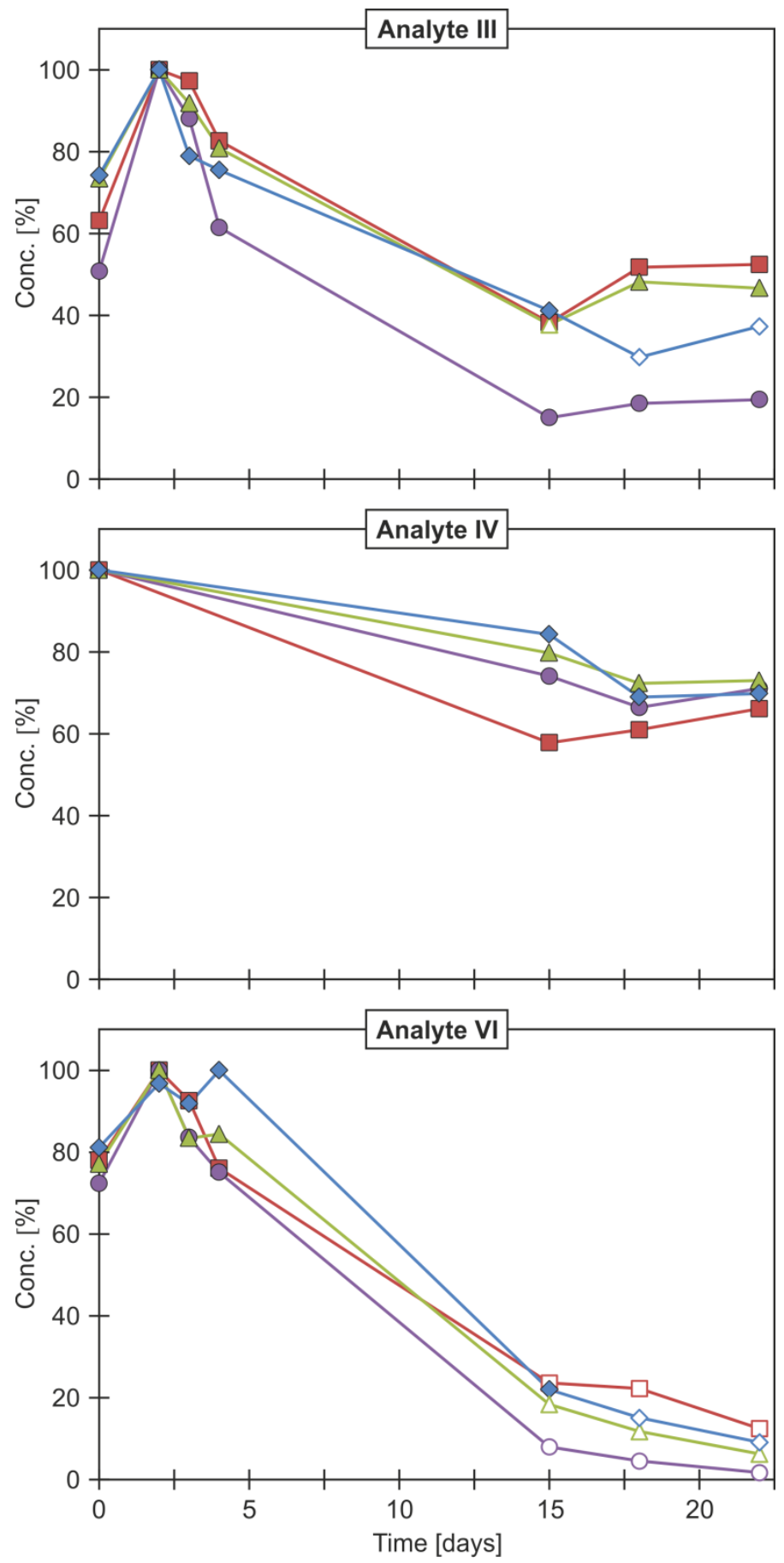

$$
\begin{aligned}
& - \text { Mineral medium }(\mathrm{C}-1) \\
& \square \text { Acetate medium }(\mathrm{C}-2) \\
& - \text { PEX extraction }(\mathrm{C}-3) \\
& \square-\text { Drinking water }(\mathrm{C}-4)
\end{aligned}
$$

Figure 4. Degradation of selected analytes in different media: Mineral medium (exp. C-1), acetate medium (exp. C-2), PEX extraction (exp. C-3) and drinking water from location 1 (exp. C-4). All measurements are means of triplicates, except exp. C-3 that are in doublets. The relative concentration was calculated from the highest concentration for each experimental set up. Hollow symbols indicate measurements below LOQ.

\subsection{Influence of locations and treatment on degradation}

The biotic and abiotic degradation in drinking water varied between different locations (experiment (D)) with iron or PEX pipes (Figure 3), although the difference 
is not big. A two-way ANOVA revealed that there was no statistical difference in abiotic and biotic degradation between the locations (Table 5). Most of the five analytes were degraded abiotically and biotically, but only analyte III, VI and VII were microbiologically degraded and analyte II and IV were not. However, the degree of abiotic and biotic degradation was low (5-38\%) after 14 days.

Table 5 - Summary of abiotic, biotic and microbiological degradation of analytes after 2 weeks incubation of drinking water from four locations spiked with analytes (exp. D). Significance of degradation given with a significance level of $5 \%$ and percentage removal of the absolute concentration.

\begin{tabular}{cccccc}
\hline \multirow{2}{*}{ Analyte } & \multicolumn{2}{c}{ Abiotic } & \multicolumn{2}{c}{ Biotic } & Microbiological \\
& Degradation & Removal & Degradation & Removal & Degradation \\
\cline { 2 - 6 } II & Yes & $14 \%$ & No & $5 \%$ & No \\
III & Yes & $33 \%$ & Yes & $38 \%$ & Yes \\
IV & Yes & $29 \%$ & Yes & $26 \%$ & No \\
VI & Yes & $20 \%$ & Yes & $34 \%$ & Yes \\
VII & No & $14 \%$ & Yes & $29 \%$ & (Yes) \\
\hline
\end{tabular}

The microorganisms from the galvanized steel installation, location 1, degraded analytes with about the same efficiency as microorganisms from the three PEX systems. Therefore, no special adaptation was necessary in order for the microorganisms to degrade the analytes. Since there were no statistical differences between the two locations (i.e. 2 and 3) supplied by the same water works, the position in the distribution system did not affect degradation of the analytes. Furthermore, degradation of analytes was similar for water supplied by the three different water works and supplied through distribution systems with proportions of PE in the range $2-100 \%$.

\subsection{Comparison of biodegradation with EPI Suite estimates}

The observed biodegradation of the analytes in drinking water, Table IV and Table V, was compared with EPI Suite estimations of the biodegradation (US EPA, 2012). Both analyte I and VI were predicted by EPI Suite calculations to biodegrade fast, which corresponded well with experimental observations for analyte I, but not for 
analyte VI. The two slowest degraded compounds (IV and BHT) in the experiments were predicted to be "not fast biodegradable" by EPI Suite. Our observations showed no biodegradation. The remaining five analytes, of which only analyte III and may be VII were partially biodegraded, were variably estimated by EPI Suite as either rapid or recalcitrantly biodegraded. The EPI Suite estimations may relate to other conditions and timeframes than drinking water, and the measured biodegradability of the analytes in our experiments was lower estimated.

\subsection{Perspectives and future studies}

The low degree of abiotic and biotic degradation observed for seven of the analytes (II, III, IV, VII, IX, XIV, and BHT) over 2-4 weeks probably means that they are hardly removed after migration to the drinking water in real water distribution systems where the residence time typically is 0.5-3 days. Only analyte I would be significantly removed in distribution systems. However, it is important to note that our degradation studies are not true simulation studies because we used water samples in glass bottles inoculated with water from distribution systems containing PE pipes. Thus, we used microcosms with suspended bacteria from real systems, not pipes from real distribution systems with biofilms on the interior surfaces. As a consequence, our studies may underestimate the rate of microbiological degradation of the analytes. Future degradation studies should include pipes/biofilms from distribution systems. This study and previous studies have demonstrated that we have only identified a few percentages of the organic matter (NVOC) migrating from PE and PEX pipes to drinking water. It is not known whether the compounds pose any problem to drinking water quality, however, chemical identification and studies of degradability as done in this study are important steps to clarify this question.

Only the removal of specific parent compounds was measured in the present study, and it is unknown whether the compounds are mineralized or transformed to other 
degradation products. Further studies on this issue are needed to assess whether unwanted degradation products are produced in drinking water.

\section{Conclusions}

* Drinking water from household installations with PEX-pipes contained analytes III, IV, VI and BHT in concentrations up to $8.0 \mu \mathrm{g} / \mathrm{L}$ after stagnation over a weekend (see analytes in Table 1).

* In a migration investigation involving incubation of water from PEX pipe, analytes III, IV, VI, VII, and IX were released in concentrations of $0.5-6.1 \mu \mathrm{g} / \mathrm{L}$, but the identified specific analytes contributed only $1.7 \%$ of the total released carbon measured as NVOC of $0.42 \pm 0.20 \mathrm{mg} / \mathrm{L}$.

* The NVOC released from the PEX pipe was a growth substrate for naturally occurring microorganisms in drinking water; however, it did not appear to stimulate degradation of the analytes. The majority (90\%) of NVOC was degraded within nine days of inoculation with drinking water.

* Eight of the nine compounds (I, II, III, IV, VI, VII, IX, XIV) were partly degraded biotically (combined abiotic and microbiological degradation) within 2-4 weeks, however, with some uncertainty with regard to compound II.

* Seven compounds were partly degraded abiotically (I, II, III, IV, VI, VII, XIV) within 2-4 weeks, however with some uncertainty with regard to compound VII.

* Significant microbiological degradation was only observed for compounds I, III, VI and may be for VII. One compound (BHT) was not significantly removed in any experiment, however indicated propensity for minor degradation.

* Despite NVOC and acetate degradation, no stimulating co-metabolic effect could be observed for any analytes nor was inhibition in drinking water observed.

* Three different drinking water sources - three water works and proportions of PE in the distribution systems of $2 \%, 50 \%$ and $100 \%$ - did not affect abiotic and biotic 
degradation of the analytes, and degradation in drinking water from a galvanized steel installation was similar to degradation in PEX installations.

* Generally, the degradation of the specific compounds was low (5-38\% over 14 days). Consequently, they would probably remain in drinking water at, or just below initial migration concentration with only minor decreases observed over a typical residence time of 0.5-3 days in a water distribution system. Analyte I was most likely to be significantly decreased before reaching the consumer due to more rapid biodegradation in comparison with the other analytes.

* In order to better simulate biodegradation rates in distribution systems, future degradation studies should be carried out with pipes from distribution systems with adapted biofilms on the interior surfaces.

* The limited degradation of the specific organic compounds released from PE and PEX pipes in combination with their octanol water coefficients calls for further studies of their significance for drinking water quality.

\section{Acknowledgments}

The authors would like to thank Professor Henrik Spliid from DTU Compute, Dept. of Applied Mathematics and Computer Science at the Technical University of Denmark, for his valuable guidance on performing ANOVA analysis using R. The authors would also like to thank laboratory technicians Christina Maj Hagberg and Sinh Hy Nguyen, Department of Environmental Engineering at Technical University of Denmark for their contribution and collaboration in the laboratory. 


\section{References}

Anselme, C., Nyguyen, K., Bruchet, A., Mallevialle, J., 1985. Characterization of low molecular weight products desorbed from polyethylene tubing. Science of the Total Environment 47, 371-384.

American Public Health Association (APHA), 1992. Total organic carbon (TOC) Persulfate-Ultraviolet Oxidation Method. Standard Methods of Water and Wastewater 18th ed.

Brocca D., Arvin, E., Mosbæk, H., 2002. Identification of organic compounds migrating from polyethylene pipelines into drinking water. Water Research 36 (15), 3675-3680.

Bucheli-Witschel, M., Kötzsch, S., Darr, S., Widler, R., Egil, T., 2012. A new method to assess the influence of migration from polymeric materials on the biostability of drinking water. Water Research 46 (13), 4246-4260.

Corfitzen, C.B., 2004. Investigation of aftergrowth potential of polymers for use in drinking water distribution. Ph.D. thesis, Environment \& Resources at Technical University of Denmark.

Corfitzen, C.B., Albrechtsen, H.-J., Arvin, E., Jørgensen, C., Boe-Hansen, R., 2002. Release of organic matter from polymer materials - microbial growth (in Danish). Miljoestyrelsen, Danish EPA project no.: 718 (2002).

Denberg, M., Mosbæk, H., Hassager, O., Arvin, E., 2009. Determination of the concentration profile and homogeneity of antioxidants and degradation products in a cross-linked polyethylene type A (PEXa) pipe. Polymer Testing 28, 378-385.

Durand, M.L., Dietrich, A.M., 2007. Contributions of silane cross-linked PEX pipe to chemical/solvent odours in drinking water. Water Science \& Technology 55 (5), 153 160. 
European Chemicals Agency, 2012. Guidance on information requirements and chemical safety assessment Chapter R.11: PBT Assessment. version 1.1.

European Commission, 2003. Technical Guidance Documents in Support of the Commission Directive 93/67/EEC on Risk Assessment for New Notified Substances and Commission Regulation, 1488/94 on Risk Assessment for Existing substances. Howard, P.H., Boethling, R.S., Stiteler, W.M., Meylan, W.M., Hueber, A.E., Beauman, J.A., Larosche, M.E., 1992. Predictive model for aerobic biodegradability developed from a file of evaluated biodegradation data. Environmental Toxicology and Chemistry 11 (5), 593-603.

Kowalska, B., Kowalski, D., Rożej, A., 2011. Organic compounds migrating from plastic pipes into water. Journal of Water Supply: Research and Technology - AQUA 60 (3), 137-146.

Lund, V., Anderson-Glenna, M., Skjevrak, I., Steffensen, I.-L., 2011. Long-term study of migration of volatile organic compounds from cross-linked polyethylene (PEX) pipes and effects on drinking water quality. Journal of Water and Health 9 (3), 483-497.

Lützhøft, H.-C.H., Waul, C.K., Andersen, H.R., Seredynska-Sobecka, B., Mosbæk, H., Christensen, N., Olsson, M.E., Arvin, E., 2013. HS-SPME-GC-MS analysis of antioxidant degradation products migrating to drinking water from PE materials and PEX pipes. International Journal of Environmental Analytical Chemistry 93 (6), 593612.

MS Excel, 2010. Part of Microsoft Office Professional Plus 2010, Microsoft Corporation, Version:14.0.7128.5000 (32-bit).

Miljoestyrelsen, 2007. Assessment of specific compounds migrated from PEX pipes (in Danish). Document no.: MST-419-00007. 
Nielsen, L.M., Fuglsang, I.A., Fischer, E.V., Hansen, N., 2007. Investigation of PEX pipes for drinking water use (in Danish). Danish EPA project no.: 1167 (2007).

R Core Team, 2014. R: A language and environment for statistical computing, $\mathrm{R}$ Foundation for Statistical Computing, Vienna, Austria, URL: www.R-project.org.

Reasoner. D.J., Geldreich, E.E., 1985. A new medium for the enumeration and subculture of bacteria from portable water. Applied and Environmental Microbiology $49(1), 1-7$.

Skjevrak, I., Due, A., Gjerstad, K.O., Herikstad, H., 2003. Volatile organic components migrating from plastic pipes (HDPE, PEX and PVC) into drinking water. Water Research 37 (8), 1912-1920.

Skjevrak, I., Lund, V., Ormerod, K., Herikstad, H., 2005. Volatile organic compounds in natural biofilm in polyethylene pipes supplied with lake water and treated water from the distribution network. Water Research 39 (17), 4133-4141.

Tsvetanova, Z.G., Hoekstra, E.J., 2009. A study on assessment of biomass production potential of pipe materials in contact with drinking water. Water Science \& Technology: Water Supply 9 (4), 423-429.

United States Environmental Protection Agency, 2012. Estimation Programs Interface (EPI) Suite ${ }^{\mathrm{TM}}$ for Microsoft® Windows, version 4.11.

Van der Kooij, D., Veenendaal, H.R., Scheffer, W.J.H., 2005. Biofilm formation and multiplication of Legionella in a model warm water system with pipes of copper, stainless steel and cross-linked polyethylene. Water Research 39 (13), 2789-2798.

Van der Kooij, D., Baggelaar, P.K., Veenendaal, H.R., Moulin, L., Corfitzen, C.B., Albrechtsen, H.J., Holt, D., Hambsch, B., 2006. Standardising the Biomass Production Potential method for determining the microbial-growth enhancement of construction products in contact with drinking water. Interlaboratory testing. European Commission. 
Vandpanelet, 2004. Leaching to drinking water from plastic pipes used for water supply - Identification of potential compounds (in Danish). Report from working group Vandpanelet, organized by DANVA, The Danish Society for Water and Wastewater (danva@danva.dk). ISBN: 87:90455-43-6.

Vang, Ó.K., Corfitzen, C.B., Smith, C., Albrechtsen, H.-J., 2014. Evaluation of ATP measurements to detect microbial ingress by wastewater and surface water in drinking water. Water Research 64, 309-320.

Villberg, K., Veijanen, A., Gustafsson, I., 1998. Identification of off-flavor compounds in high-density polyethylene (HDPE) with different amounts of abscents. Polymer Engineering and Science 38 (8), 922-925. 